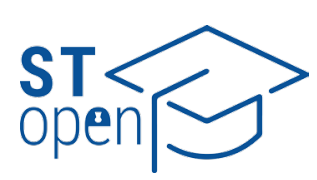

(c) 2020 The Author(s)

\title{
Accuracy of measurements performed on digital panoramic radiographs with and without an extra-oral calibration object
}

\author{
Anita Ivanović (1), \\ Frane Mihanović \\ Department of Health Sciences \\ University of Split, Split, Croatia
}

\begin{abstract}
Aim: To investigate the accuracy of measurements in vertical and horizontal direction using an extra-oral calibration object placed in different positions on the panoramic radiograph in JPEG and DICOM image format.

Methods: Digital panoramic radiographs of a purpose made model with 32 removable teeth replaced with metal balls were taken. The measurements of metal balls were performed with and without the calibration object placed in the middle or on the side of the radiograph in JPEG and DICOM image formats.
\end{abstract}

\begin{abstract}
Results: One sample t-test was used for the analyses of accuracy of measurements in vertical and horizontal direction. The most accurate vertical measurements were achieved in canine group in JPEG $(6.02 \pm 0.04 \mathrm{~mm}, P=0.144)$ and DICOM (6.03 $\pm 0.07 \mathrm{~mm}, P=0.104)$ formats using calibration object placed in the middle of the radiograph. The mean values of measurements in horizontal direction differed significantly from the real values $(P<0.05)$ in all teeth groups regardless of the image format.

Conclusion: The most accurate measurements in vertical direction were achieved by placing the metal scale ruler extra-orally in the middle of panoramic radiograph independent of the image format. Reliable clinical accuracy for measurements in horizontal direction was achieved only in canine region (G2) in both image formats.
\end{abstract}

\section{Introduction}

Panoramic radiography is commonly used imaging modality representing a valuable diagnostic tool in the dental clinical practice [1]. Widely available, at relatively low cost, it allows visualization of dentoalveolar anatomy of both dental arches with low radiation dose [2-5]. The panoramic radiograph also depicts numerous anatomic structures outside jaws, creating further interpretation challenges for dental clinicians [1]. Additionally, pan- 
oramic radiographs are standard examination tools for the assessment of bone architecture and are useful in planning of the initial diagnostic phase of the implant treatment [5]. It may also be indicated for the purpose of postoperative assessment and periodic review of implants [5]. Cone-beam computed tomography (CBCT) is required for preoperative cross-sectional imaging when clinical conditions indicate a need for augmentation procedures and bone reconstruction prior to the implant placement. In addition, CBCT is indicated as postoperative imaging technique only if the patient presents the implant mobility [5].

Dental clinicians in their daily practice are faced with different image formats: Joint Photographic Experts Group (JPEG), Joint Photographic Experts Group 2000 (JPEG 2000), Tagged Image File Format (TIFF), Graphics Interchange Format (GIF), Portable Network Graphics (PNG), and Digital Imaging and Communication in Medicine (DICOM) [4]. Each image format has characteristic advantages and disadvantages e.g. JPEG format can be opened with different viewers while DICOM format can be opened with specific DICOM viewer. Both image formats have to be considered while using images for clinical, educational or scientific purposes [6-8]. Panoramic radiography allows performance of measurements on digital images using different software but users must be aware of their characteristics (including certain imperfections).

Image distortion, due to variations in a degree of magnification in horizontal and vertical planes, may affect the accuracy of linear measurements in panoramic radiographs $[9,10]$.

The aim of this study was to investigate the accuracy of measurements in vertical and horizontal planes/directions using an extra-oral calibration object (metal scale ruler) placed in different areas on a panoramic radiograph in two standard image formats (JPEG and DICOM). We also investigated the distortion of images in different regions of the mandible and the maxilla. We hypothesized that the extra-oral calibration of digital panoramic radiographs will improve the accuracy of measurements performed in dental practice independently of the image format.

\section{Methods}

In this test-model study the Transparent Demonstration Model (Hager\&Werken GmbH, Duisburg, Germany Ref: 355641) was used. The life size modelhad 32 removable teeth which were replaced with 32 metal balls $6 \mathrm{~mm}$ in diameter. Each metal ball was embedded in a block of silicone impression material (ExpressTM STD, 3M ESPE Deutchland $\mathrm{GmbH}$, Dental products, Neuss, Germany) and inserted in alveoli, in natural teeth position. The model with 32 inserted metal balls was imaged in a digital panoramic X-ray unit Orthopantomograph OP 200D (Instrumentarium Dental, Tuusula, Finland) in the Center for Dental Radiology X-Dent, Split, Croatia. During imaging, the model was fixed on the chin rest of the digital panoramic X-ray unit with the adhesive bandage to avoid any movement (Figure 1). It was centered in the midline of the panoramic X-ray unit and was placed horizontally perpendicular to the midline, using the laser light beam as a guide. The oilbased clay (Plastelin, TOZ Penkala, Zagreb, Croatia) was placed on the inside front region of the mandible to equalize attenuation of radiation. The X-ray tube was operated with 
settings of $66 \mathrm{kVp}, 5.0 \mathrm{~mA}$ and an exposure time of 14.1 seconds. Panoramic examinations were performed by the same radiographer.

A metal scale ruler of known length $(50 \mathrm{~mm}$ ) (Nasion Support ref., 6445 IMG, Instrumentarium Dental, Tuusula, Finland) was used as an extra-oral calibration object. It was placed on the holder of the chin rest in the middle of the model either in a vertical position or laterally on the side mark holder of the panoramic X-ray unit. It was fixed firmly with the oil-based clay (Plastelin, TOZ Penkala, Zagreb, Croatia) (in the middle) or with the rubber (on the side).

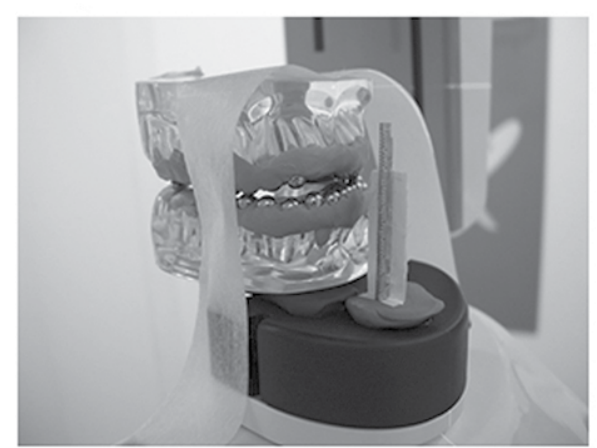

a1

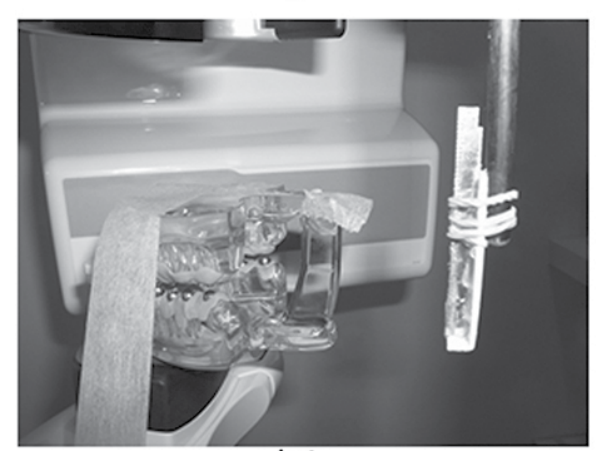

b1

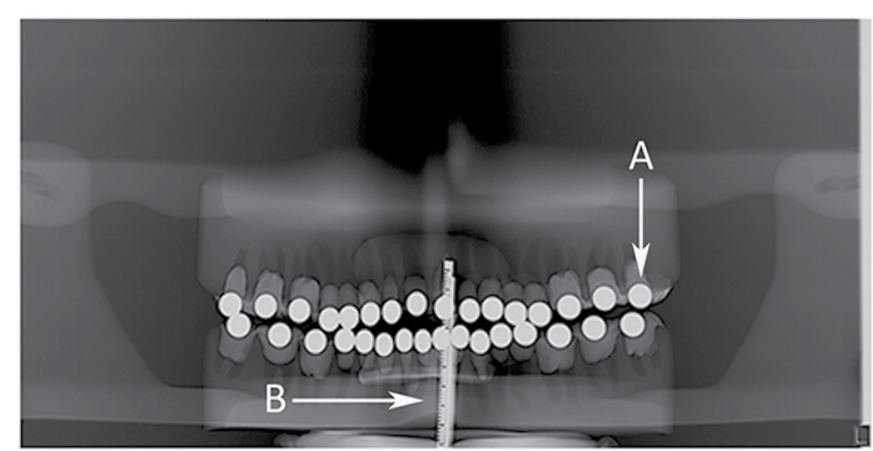

a2

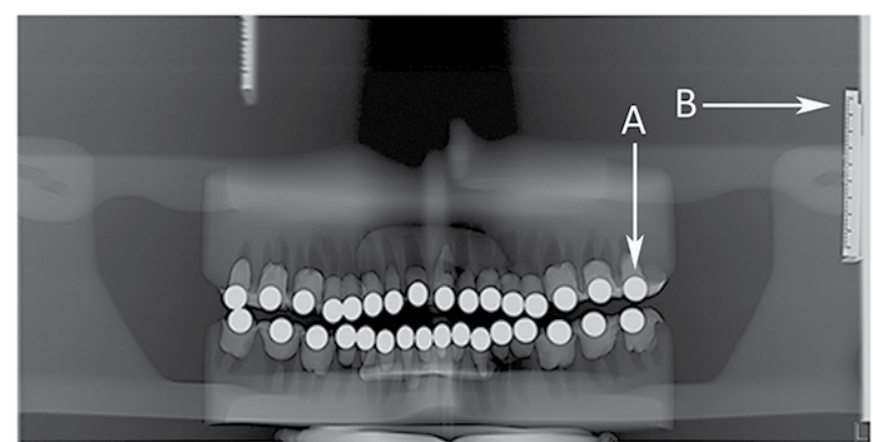

b2

Figure 1. Transparent demonstration model with 32 inserted metal balls placed on the chinrest of the digital panoramic unit with the metal scale ruler placed in the middle of the model (a1); (a2) panoramic radiograph of the model with metal scale ruler placed in the middle; A: metal ball; B: metal scale ruler; (b1) Transparent demonstration model with 32 metal balls inserted placed on the chin rest of the digital panoramic unit with the metal scale ruler placed laterally on the side mark holder; (b2) panoramic radiograph of the model with the metal scale ruler placed on the side; A: metal ball; B: metal scale ruler.

Three different images of the model were taken: without the calibration object, with the calibration object placed in the middle of the panoramic radiograph, and one image with the calibration object placed on the side.

The files were saved in DICOM image format in the center image archiving and communication database and converted in JPEG image format for later analyses. The images were delivered through a Picture Archiving and Communication System (PACS) (DICOM) and e-mailed (JPEG) to a personal computer (MacBook Pro 15.4“, Apple, Cupertino, USA) where it was analyzed using the dental imaging software package CliniView 10.0.1.8 with the DICOM viewer, version 2.6.2.1. (Instrumentaruim Dental, Tuusula, Finland), and integrated calibration tool, which automatically calculated the distance between the selected points to the nearest tenth of a millimeter. The same software was used for all measurements, in 
DICOM and JPEG image format with 100\% image magnification and identical contrast and brightness. Readings were recorded by the observer and stored as computer files.

\section{Metal ball length evaluation}

All panoramic radiographs were analyzed separately by three independent observers experienced in image interpretation and all three were blind to other observers' results. One observer was general dental practitioner with 15 years of clinical experience in dentistry. The other two observers were radiographers, experienced in medical radiology and trained in the field of dental radiography. Each image set (JPEG image format without the calibration, JPEG image format with calibration object in the middle, JPEG image format with calibration object on the side, DICOM image format with calibration object in the middle and DICOM image format with calibration object on the side) was analyzed twice, in a random order, in a different sessions at 2-week interval between viewing, to eliminate memory bias. Prior to the official measurements, the observers practiced using the software on the radiographs, which were not part of this study, in order to get familiar with its functions. Each observer examined the largest horizontal and vertical distance on each of 32 metal balls, randomly, on 5 different radiographs using a mouse-driven pointer (Figure 2).

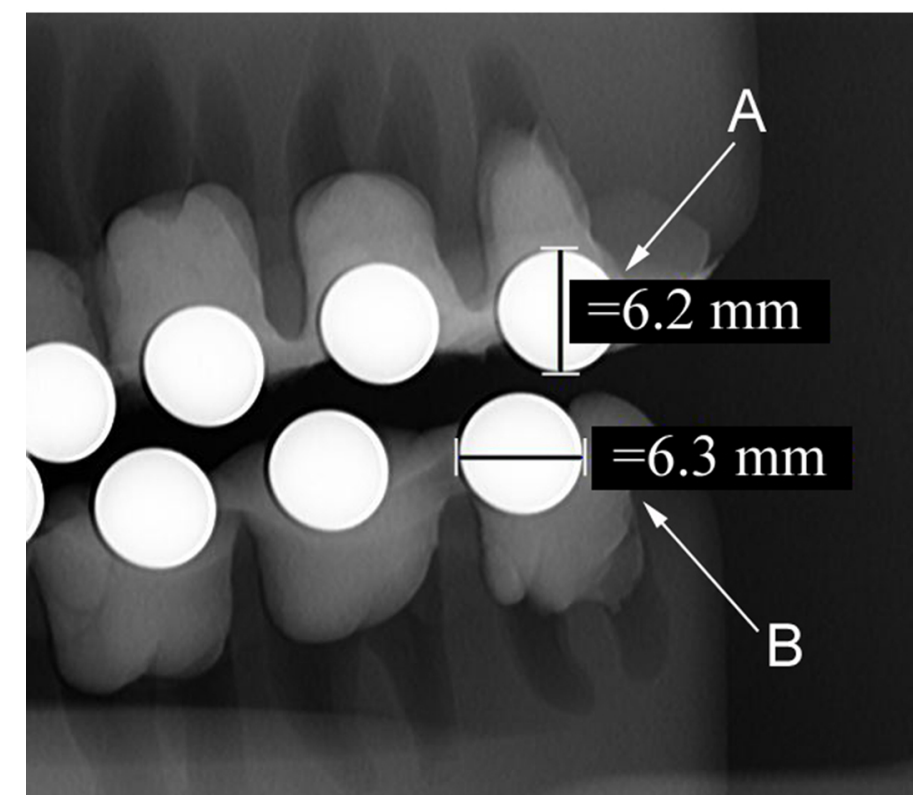

Figure 2. Measurements of the (A) vertical and (B) horizontal dimension of the metal ball on digital panoramic radiograph using dental imaging software.

Because of different image distortion in different panoramic radiograph regions, we divided measurements in four groups according to the teeth position in dental arch (tooth numbering): incisors (11, 12, 21, 22, 31, 32, 41, 42), canines (13, 23, 33, 43), premolars (14, 15, 24, 25, 34, 35, 44, 45) and molars (16, 17, 18, 26, 27, 28, 36, 37, 38, 46, 47, 48).

\section{Statistical analysis}

Statistical analysis was performed with MedCalc for Windows, version 11.5.1.0 (MedCalc Software, Mariakerke, Belgium). Intra and inter-class reliability was assessed with the 
Bland-Altman method by calculating the Interclass correlation coefficient (ICC). Data were presented as mean \pm standard deviation and as median with range (minimum - maximum) for each group separately. One sample t-test was used for the analyses of differences between measured and real values of 32 metal balls in different teeth groups and measurement methods. The distortion ratio (DR) was calculated for measurements of each metal ball for vertical and horizontal plane as follows:

$$
\mathrm{DR}=\frac{\text { (radiological metal ball diameter }(\mathrm{mm}))}{\text { (real metal ball diameter }(6 \mathrm{~mm}))}
$$

in four groups of teeth positions (Incisors, Canines, Premolars, Molars) [11]. The significance level was set at $P<0.05$.

\section{Results}

\section{Inter- and intra-observer reliability}

Overall Interclass correlation coefficient (ICC) revealed high degree of inter- and intra- reliability between the observers and measurement sessions for all results (ICC $=0.997,95 \%$ confidence interval (CI) $0.996-0.997, P<0.001$ ) (Figure 3). ICC between Observer 1 and Observer 2 was 0.991 , between Observer 1 and Observer 30.992 and between Observer 2 and Observer 3 0.989, showing acceptable inter-agreements. The interpretation of the intra-observer agreement was similar to the inter-observer agreement.

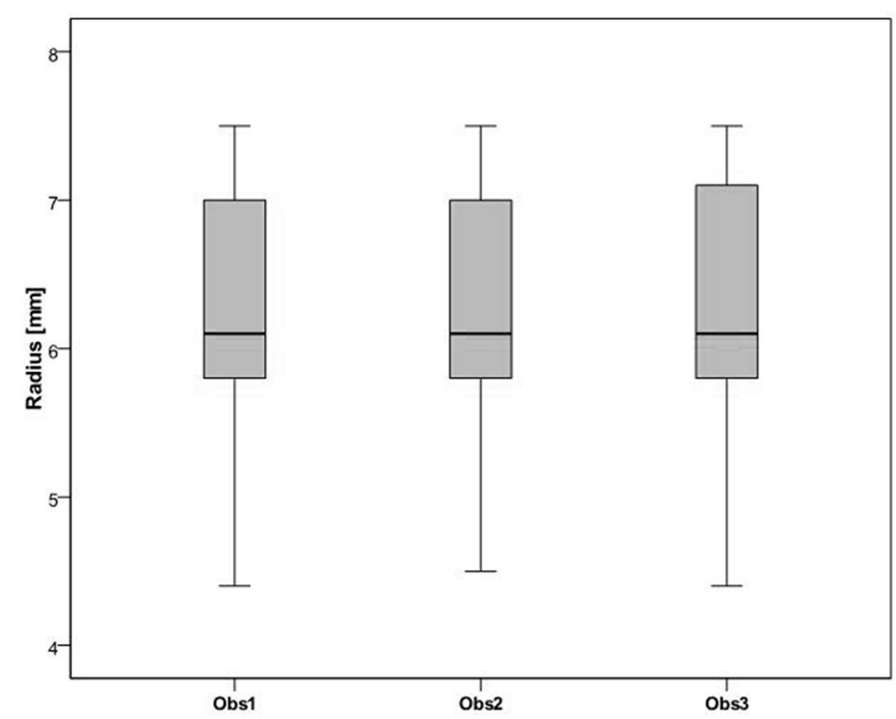

Figure 3. Overall distribution of the measured metal balls' diameters between the three observers (Obs).

\section{Overall accuracy of vertical and horizontal measurements of 32 metal balls with or without the calibration object in JPEG and DICOM image format}

The accuracy of measurements of 32 metal balls ( $6 \mathrm{~mm}$ diameter) showed differences related to the measurement method (with or without the extra-oral calibration object), group of the teeth measured (incisors, canines, premolars, molars) and the plane of the 
measurement (vertical or horizontal). Overall results of the accuracy of measurements are shown in Table 1.

Table 1. Overall results of vertical and horizontal measurements of 32 metal balls with or without thecalibrationobjectin JPEG and DICOM image format

\begin{tabular}{|c|c|c|c|c|c|c|c|c|c|c|c|c|}
\hline \multirow{3}{*}{$\begin{array}{l}\text { Measurement } \\
\text { method (mm) }\end{array}$} & \multicolumn{12}{|c|}{ Vertical measurement } \\
\hline & \multicolumn{3}{|c|}{ Incisors (G1) } & \multicolumn{3}{|c|}{ Canines (G2) } & \multicolumn{3}{|c|}{ Premolars (G3) } & \multicolumn{3}{|c|}{ Molars (G4) } \\
\hline & $\begin{array}{c}\text { Mean } \pm \\
\text { SD }\end{array}$ & $\begin{array}{l}\text { Median } \\
\text { (min;- } \\
\text { max) }\end{array}$ & $P^{*}$ & $\begin{array}{c}\text { Mean } \pm \\
\text { SD }\end{array}$ & $\begin{array}{l}\text { Median } \\
\text { (min;- } \\
\text { max) }\end{array}$ & $P^{*}$ & $\begin{array}{l}\text { Mean士 } \\
\text { SD }\end{array}$ & $\begin{array}{l}\text { Median } \\
\text { (min;- } \\
\max \text { ) }\end{array}$ & $P *$ & $\begin{array}{c}\text { Mean } \pm \\
\text { SD }\end{array}$ & $\begin{array}{l}\text { Median } \\
\text { (min;- } \\
\text { max) }\end{array}$ & $P *$ \\
\hline JPEG 1 & $5.86 \pm 0.05$ & $\begin{array}{c}5.90 \\
(5.80 ; 5.90)\end{array}$ & $<0.001$ & $5.85 \pm 0.05$ & $\begin{array}{c}5.85 \\
(5.80 ; 5.90)\end{array}$ & $<0.001$ & $5.93 \pm 0.08$ & $\begin{array}{c}5.90 \\
(5.80 ; 6.10)\end{array}$ & $<0.001$ & $6.04 \pm 0.07$ & $\begin{array}{c}6.05 \\
(5.90 ; 6.10)\end{array}$ & 0.005 \\
\hline JPEG 2 & $6.03 \pm 0.06$ & $\begin{array}{c}6.00 \\
(5.90 ; 6.10)\end{array}$ & 0.056 & $6.02 \pm 0.04$ & $\begin{array}{c}6.00 \\
(6.00 ; 6.10)\end{array}$ & 0.166 & $6.11 \pm 0.07$ & $\begin{array}{c}6.10 \\
(6.00 ; 6.20)\end{array}$ & $<0.001$ & $6.21 \pm 0.10$ & $\begin{array}{c}6.20 \\
(6.00 ; 6.40)\end{array}$ & $<0.001$ \\
\hline DICOM 2 & $6.04 \pm 0.07$ & $\begin{array}{c}6.00 \\
(6.00 ; 6.20)\end{array}$ & 0.017 & $6.03 \pm 0.07$ & $\begin{array}{c}6.00 \\
(6.00 ; 6.20)\end{array}$ & 0.104 & $6.12 \pm 0.07$ & $\begin{array}{c}6.10 \\
(6.00 ; 6.20)\end{array}$ & $<0.001$ & $6.22 \pm 0.09$ & $\begin{array}{c}6.20 \\
(6.00 ; 6.40)\end{array}$ & $<0.001$ \\
\hline JPEG 3 & $7.09 \pm 0.07$ & $\begin{array}{c}7.10 \\
(7.00 ; 7.20)\end{array}$ & $<0.001$ & $7.09 \pm 0.05$ & $\begin{array}{c}7.10 \\
(7.00 ; 7.20)\end{array}$ & $<0.001$ & $7.15 \pm 0.08$ & $\begin{array}{c}7.20 \\
(7.00 ; 7.30)\end{array}$ & $<0.001$ & $7.29 \pm 0.09$ & $\begin{array}{c}7.30 \\
(7.10 ; 7.50)\end{array}$ & $<0.001$ \\
\hline DICOM 3 & $7.08 \pm 0.08$ & $\begin{array}{c}7.10 \\
(7.00 ; 7.30)\end{array}$ & $<0.001$ & $7.07 \pm 0.07$ & $\begin{array}{c}7.10 \\
(7.00 ; 7.20)\end{array}$ & $<0.001$ & $7.17 \pm 0.10$ & $\begin{array}{c}7.20 \\
(7.00 ; 7.30)\end{array}$ & $<0.001$ & $7.26 \pm 0.08$ & $\begin{array}{c}7.30 \\
(7.10 ; 7.50)\end{array}$ & $<0.001$ \\
\hline \multirow{3}{*}{$\begin{array}{l}\text { Measurement } \\
\text { methods } \\
(\mathrm{mm})\end{array}$} & \multicolumn{12}{|c|}{ Horizontal measurement } \\
\hline & \multicolumn{3}{|c|}{ Incisors (G1) } & \multicolumn{3}{|c|}{ Canines (G2) } & \multicolumn{3}{|c|}{ Premolars (G3) } & \multicolumn{3}{|c|}{ Molars (G4) } \\
\hline & $\begin{array}{c}\text { Mean } \pm \\
\text { SD }\end{array}$ & $\begin{array}{l}\text { Median } \\
\text { (min;- } \\
\text { max) }\end{array}$ & $P *$ & $\begin{array}{c}\text { Mean } \pm \\
\text { SD }\end{array}$ & $\begin{array}{l}\text { Median } \\
\text { (min;- } \\
\text { max) }\end{array}$ & $P^{*}$ & $\begin{array}{l}\text { Mean士 } \\
\text { SD }\end{array}$ & $\begin{array}{l}\text { Median } \\
\text { (min;- } \\
\text { max) }\end{array}$ & $P^{*}$ & $\begin{array}{c}\text { Mean } \pm \\
\text { SD }\end{array}$ & $\begin{array}{l}\text { Median } \\
\text { (min;- } \\
\text { max) }\end{array}$ & $P^{*}$ \\
\hline JPEG 1 & $4.76 \pm 0.30$ & $\begin{array}{c}4.80 \\
(4.40 ; 5.30)\end{array}$ & $<0.001$ & $5.08 \pm 0.30$ & $\begin{array}{c}5.05 \\
(4.70 ; 5.60)\end{array}$ & $<0.001$ & $5.39 \pm 0.42$ & $\begin{array}{c}5.35 \\
(4.70 ; 6.00)\end{array}$ & $<0.001$ & $5.90 \pm 0.23$ & $\begin{array}{c}6.00 \\
(5.50 ; 6.20)\end{array}$ & 0.012 \\
\hline JPEG 2 & $4.95 \pm 0.29$ & $\begin{array}{c}4.95 \\
(4.50 ; 5.40)\end{array}$ & $<0.001$ & $5.23 \pm 0.35$ & $\begin{array}{c}5.20 \\
(4.80 ; 5.80)\end{array}$ & $<0.001$ & $5.55 \pm 0.45$ & $\begin{array}{c}5.60 \\
(4.80 ; 6.20)\end{array}$ & $<0.001$ & $6.09 \pm 0.21$ & $\begin{array}{c}6.10 \\
(5.70 ; 6.40)\end{array}$ & 0.021 \\
\hline DICOM 2 & $4.97 \pm 0.30$ & $\begin{array}{c}4.95 \\
(4.50 ; 5.50)\end{array}$ & $<0.001$ & $5.21 \pm 0.36$ & $\begin{array}{c}5.15 \\
(4.70 ; 5.90)\end{array}$ & $<0.001$ & $5.58 \pm 0.45$ & $\begin{array}{c}5.60 \\
(4.80 ; 6.20)\end{array}$ & $<0.001$ & $6.08 \pm 0.21$ & $\begin{array}{c}6.10 \\
(5.60 ; 6.40)\end{array}$ & 0.033 \\
\hline JPEG 3 & $5.60 \pm 0.32$ & $\begin{array}{c}5.60 \\
(5.20 ; 6.20)\end{array}$ & $<0.001$ & $6.05 \pm 0.34$ & $\begin{array}{c}6.05 \\
(5.60 ; 6.60)\end{array}$ & 0.618 & $6.43 \pm 0.49$ & $\begin{array}{c}6.45 \\
(5.60 ; 7.20)\end{array}$ & $<0.001$ & $7.11 \pm 0.28$ & $\begin{array}{c}7.20 \\
(6.60 ; 7.50)\end{array}$ & $<0.001$ \\
\hline DICOM 3 & $5.57 \pm 0.29$ & $\begin{array}{c}5.60 \\
(5.20 ; 6.00)\end{array}$ & $<0.001$ & $6.03 \pm 0.36$ & $\begin{array}{c}6.00 \\
(5.40 ; 6.50)\end{array}$ & 0.817 & $6.38 \pm 0.53$ & $\begin{array}{c}6.40 \\
(5.40 ; 7.10)\end{array}$ & 0.002 & $7.06 \pm 0.27$ & $\begin{array}{c}7.10 \\
(6.60 ; 7.50)\end{array}$ & $<0.001$ \\
\hline
\end{tabular}

SD - standard deviation

* One sample t-test between measured and real values of 32 metal balls in different teeth groups and measurement methods. JPEG 1, JPEG image without calibration; JPEG 2, JPEG image with the metal ruler in the middle; DICOM 2, DICOM image with the metal ruler in the middle; JPEG 3, JPEG image with the metal ruler over the side; DICOM 3, DICOM image with the metal ruler over the side.

Results of measurements of 32 metal balls performed in vertical and in horizontal directions in non-calibrated JPEG format differed significantly from the real metal ball diameter $(6 \mathrm{~mm})$ in all teeth groups $(P<0.05)$.

When JPEG image format with the calibration object positioned in the middle of the radiograph were assessed by performing vertical and horizontal measurements of 32 metal balls ( $6 \mathrm{~mm}$ diameter), the mean vertical values were $6.03 \pm 0.06 \mathrm{~mm}(P=0.056)$ in incisor group and $6.02 \pm 0.04 \mathrm{~mm}(P=0.144)$ in canine group, while vertical measurements in premolar and molar groups differed significantly from the real metal ball diameter $(P<0.05)$. The mean values of horizontal measurements of 32 metal balls differed significantly $(P<0.05)$ from the real values $(6 \mathrm{~mm})$ in all teeth groups.

When using DICOM image format with the calibration object positioned in the middle of the radiograph the most accurate vertical measurements were in the canine group (6.03 $\pm 0.07 \mathrm{~mm}, P=0.104)$. 
Vertical and horizontal measurements with the calibration object placed on the side of the image differed significantly from the real values in all teeth groups and in both used image formats $(P<0.05)$ with the exception for horizontal measurements in canine group in JPEG (6.05 $\pm 0.34, P=0.618)$ and DICOM (6.03 $\pm 0.36, P=0.817)$ image formats.

The overall differences from the mean values of ball measurements performed in both directions with the calibration object placed in different extra-oral positions of the radiograph in JPEG and DICOM image formats are shown in Table 2.

Table 2. Overall results of vertical and horizontal measurements of 32 metal balls with or without thecalibrationobjectin JPEG and DICOM image foOverall mean differences from the mean values of vertical and horizontal metal ball measurements with or without the calibration object placed in different extra-oral positions of the panoramic radiograph in JPEG and DICOM image formats

\begin{tabular}{|c|c|c|c|c|c|c|c|c|}
\hline \multirow{3}{*}{$\begin{array}{l}\text { Image } \\
\text { format* }\end{array}$} & \multicolumn{8}{|c|}{ Vertical measurement } \\
\hline & \multicolumn{2}{|c|}{ Incisors (G1) } & \multicolumn{2}{|c|}{ Canines (G2) } & \multicolumn{2}{|c|}{ Premolars (G3) } & \multicolumn{2}{|c|}{ Molars (G4) } \\
\hline & MD & $95 \% \mathrm{Cl}$ & MD & $95 \% \mathrm{Cl}$ & MD & $95 \% \mathrm{Cl}$ & MD & $95 \% \mathrm{Cl}$ \\
\hline JPEG 1 & -0.14 & $-0.16,-0.12$ & 0.15 & $-0.18,-0.12$ & -0.07 & $-0.10,-0.04$ & 0.04 & $0.01,0.06$ \\
\hline JPEG 2 & 0.02 & $0.00,0.05$ & 0.02 & $-0.01,0.04$ & 0.11 & $0.08,0.14$ & 0.21 & $0.18,0.25$ \\
\hline DICOM 2 & 0.04 & $0.01,0.07$ & 0.03 & $-0.01,0.07$ & 0.12 & $0.09,0.15$ & 0.22 & $0.19,0.25$ \\
\hline JPEG 3 & 1.09 & $1.06,1.12$ & 1.09 & $1.06,1.12$ & 1.15 & $1.12,1.19$ & 1.29 & $1.26,1.32$ \\
\hline DICOM 3 & 1.08 & $1.05,1.12$ & 1.07 & $1.03,1.11$ & 1.17 & $1.13,1.21$ & 1.26 & $1.24,1.29$ \\
\hline \multirow{3}{*}{$\begin{array}{c}\text { Image } \\
\text { format* }\end{array}$} & \multicolumn{8}{|c|}{ Horizontal measurement } \\
\hline & \multicolumn{2}{|c|}{ Incisors (G1) } & \multicolumn{2}{|c|}{ Canines (G2) } & \multicolumn{2}{|c|}{ Premolars (G3) } & \multicolumn{2}{|c|}{ Molars (G4) } \\
\hline & MD & $95 \% \mathrm{Cl}$ & MD & $95 \% \mathrm{Cl}$ & MD & $95 \% \mathrm{Cl}$ & MD & $95 \% \mathrm{Cl}$ \\
\hline JPEG 1 & -1.24 & $-1.37,-1.11$ & -0.92 & $-1.11,-0.73$ & -0.61 & $-0.79,-0.44$ & -0.10 & $-0.18,-0.02$ \\
\hline JPEG 2 & -1.05 & $-1.17,-0.93$ & -0.77 & $-0.99,-0.55$ & -0.45 & $-0.63,-0.26$ & 0.09 & $0.01,0.16$ \\
\hline DICOM 2 & -1.03 & $-1.16,-0.91$ & -0.79 & $-1.02,-0.56$ & -0.43 & $-0.62,-0.23$ & 0.08 & $0.01,0.15$ \\
\hline JPEG 3 & -0.40 & $-0.53,-0.26$ & 0.05 & $-0.16,0.26$ & 0.43 & $0.22,0.63$ & 1.11 & $1.02,1.21$ \\
\hline DICOM 3 & -0.43 & $-0.56,-0.31$ & 0.02 & $-0.21,0.26$ & 0.38 & $0.16,0.60$ & 1.06 & $0.96,1.15$ \\
\hline
\end{tabular}

$\mathrm{MD}$ - mean differences; $\mathrm{Cl}$ - confidence interval

*JPEG 1, JPEG image without calibration; JPEG 2, JPEG image with the metal ruler in the middle; DICOM 2, DICOM image with the metal ruler in the middle; JPEG 3, JPEG image with the metal ruler on the side; DICOM 3, DICOM image with the metal ruler on the side.

\section{Distortion ratio (DR) of 32 metal balls with or without the calibration in JPEG and DICOM image format}

Image distortion is a result of specific geometric projections of panoramic radiography. The values of the calculated metal balls DRs are in accordance with the real measurement values. Distribution of DRs with or without the calibration in different image formats are shown in Table 3. 
Table 3. Distortion ratio of 32 metal balls with or without the calibration in JPEG and DICOM image format

\begin{tabular}{|c|c|c|c|c|c|c|c|c|c|c|c|}
\hline \multirow{3}{*}{$\begin{array}{c}\text { Plane } \\
\text { measure- } \\
\text { ment }\end{array}$} & \multirow{3}{*}{$\begin{array}{l}\text { Teeth } \\
\text { group }\end{array}$} & \multicolumn{10}{|c|}{ Image format* } \\
\hline & & \multicolumn{2}{|c|}{ JPEG 1} & \multicolumn{2}{|c|}{ JPEG 2} & \multicolumn{2}{|c|}{ DICOM 2} & \multicolumn{2}{|c|}{ JPEG 3} & \multicolumn{2}{|c|}{ DICOM 3} \\
\hline & & $\begin{array}{l}\text { Mean } \pm \\
\text { SD }\end{array}$ & $\begin{array}{l}\text { Median } \\
\text { (min;- } \\
\text { max) }\end{array}$ & $\begin{array}{l}\text { Mean } \pm \\
\text { SD }\end{array}$ & $\begin{array}{c}\text { Median } \\
\text { (min;- } \\
\text { max) }\end{array}$ & $\begin{array}{l}\text { Mean } \pm \\
\text { SD }\end{array}$ & $\begin{array}{c}\text { Median } \\
\text { (min;- } \\
\max )\end{array}$ & $\begin{array}{l}\text { Mean } \pm \\
\text { SD }\end{array}$ & $\begin{array}{c}\text { Median } \\
(\min ;- \\
\max )\end{array}$ & $\begin{array}{l}\text { Mean } \pm \\
\text { SD }\end{array}$ & $\begin{array}{c}\text { Median } \\
\text { (min;- } \\
\text { max) }\end{array}$ \\
\hline \multirow{4}{*}{ 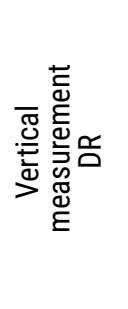 } & Incisors & $0.98 \pm 0.01$ & $\begin{array}{c}0.98 \\
(0.97 ; 0.98)\end{array}$ & $1.00 \pm 0.01$ & $\begin{array}{c}1.00 \\
(0.98 ; 1.02)\end{array}$ & $1.01 \pm 0.01$ & $\begin{array}{c}1.00 \\
(1.00 ; 1.03)\end{array}$ & $1.18 \pm 0.01$ & $\begin{array}{c}1.18 \\
(1.17 ; 1.20)\end{array}$ & $1.18 \pm 0.01$ & $\begin{array}{c}1.18 \\
(1.17 ; 1.22)\end{array}$ \\
\hline & Canines & $0.97 \pm 0.01$ & $\begin{array}{c}0.97 \\
(0.97 ; 0.98)\end{array}$ & $1.00 \pm 0.01$ & $\begin{array}{c}1.00 \\
(1.00 ; 1.02)\end{array}$ & $1.01 \pm 0.01$ & $\begin{array}{c}1.00 \\
(1.00 ; 1.03)\end{array}$ & $1.18 \pm 0.01$ & $\begin{array}{c}1.18 \\
(1.17 ; 1.20)\end{array}$ & $1.18 \pm 0.01$ & $\begin{array}{c}1.18 \\
(1.17 ; 1.20)\end{array}$ \\
\hline & Premolars & $0.99 \pm 0.01$ & $\begin{array}{c}0.98 \\
(0.97 ; 1.02)\end{array}$ & $1.02 \pm 0.01$ & $\begin{array}{c}1.02 \\
(1.00 ; 1.03)\end{array}$ & $1.02 \pm 0.01$ & $\begin{array}{c}1.02 \\
(1.00 ; 1.03)\end{array}$ & $1.19 \pm 0.01$ & $\begin{array}{c}1.20 \\
(1.17 ; 1.22)\end{array}$ & $1.20 \pm 0.02$ & $\begin{array}{c}1.20 \\
(1.17 ; 1.22)\end{array}$ \\
\hline & Molars & $1.01 \pm 0.01$ & $\begin{array}{c}1.01 \\
(0.98 ; 1.02)\end{array}$ & $1.04 \pm 0.02$ & $\begin{array}{c}1.03 \\
(1.00 ; 1.07)\end{array}$ & $1.04 \pm 0.02$ & $\begin{array}{c}1.03 \\
(1.00 ; 1.07)\end{array}$ & $1.22 \pm 0.01$ & $\begin{array}{c}1.22 \\
(1.18 ; 1.25)\end{array}$ & $1.21 \pm 0.01$ & $\begin{array}{c}1.22 \\
(1.18 ; 1.25)\end{array}$ \\
\hline \multirow{4}{*}{ 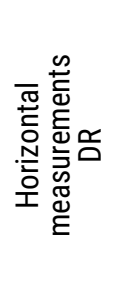 } & Incisors & $0.79 \pm 0.05$ & $\begin{array}{c}0.80 \\
(0.73 ; 0.88)\end{array}$ & $0.83 \pm 0.05$ & $\begin{array}{c}0.82 \\
(0.75 ; 0.90)\end{array}$ & $0.83 \pm 0.05$ & $\begin{array}{c}0.82 \\
(0.75 ; 0.92)\end{array}$ & $0.93 \pm 0.05$ & $\begin{array}{c}0.93 \\
(0.87 ; 1.03)\end{array}$ & $0.93 \pm 0.05$ & $\begin{array}{c}0.93 \\
(0.87 ; 1.00)\end{array}$ \\
\hline & Canines & $0.85 \pm 0.05$ & $\begin{array}{c}0.84 \\
(0.78 ; 0.93)\end{array}$ & $0.87 \pm 0.06$ & $\begin{array}{c}0.87 \\
(0.80 ; 0.97)\end{array}$ & $0.87 \pm 0.06$ & $\begin{array}{c}0.86 \\
(0.78 ; 0.98)\end{array}$ & $1.01 \pm 0.06$ & $\begin{array}{c}1.01 \\
(0.93 ; 1.10)\end{array}$ & $1.00 \pm 0.06$ & $\begin{array}{c}1.00 \\
(0.90 ; 1.08)\end{array}$ \\
\hline & Premolars & $0.90 \pm 0.07$ & $\begin{array}{c}0.89 \\
(0.78 ; 1.00)\end{array}$ & $0.93 \pm 0.07$ & $\begin{array}{c}0.93 \\
(0.80 ; 1.03)\end{array}$ & $0.93 \pm 0.08$ & $\begin{array}{c}0.93 \\
(0.80 ; 1.03)\end{array}$ & $1.07 \pm 0.08$ & $\begin{array}{c}1.08 \\
(0.93 ; 1.20)\end{array}$ & $1.06 \pm 0.09$ & $\begin{array}{c}1.07 \\
(0.90 ; 1.18)\end{array}$ \\
\hline & Molars & $0.98 \pm 0.04$ & $\begin{array}{c}1.00 \\
(0.92 ; 1.03)\end{array}$ & $1.01 \pm 0.04$ & $\begin{array}{c}1.02 \\
(0.95 ; 1.07)\end{array}$ & $1.01 \pm 0.03$ & $\begin{array}{c}1.02 \\
(0.93 ; 1.07)\end{array}$ & $1.19 \pm 0.05$ & $\begin{array}{c}1.20 \\
(1.10 ; 1.25)\end{array}$ & $1.18 \pm 0.04$ & $\begin{array}{c}1.18 \\
(1.10 ; 1.25)\end{array}$ \\
\hline
\end{tabular}

SD - standard deviation; $\mathrm{DR}$ - distortion ratio

*JPEG 1, JPEG image without calibration; JPEG 2, JPEG image with the metal ruler in the middle; DICOM 2, DICOM image with the metal ruler in the middle; JPEG 3, JPEG image with the metal ruler overside; DICOM 3, DICOM image with the metal ruler over side.

\section{Discussion}

In this study we used the metal scale ruler placed extra-orally so that it appears in the middle of the panoramic radiograph as the most accurate calibration object [22]. In our study vertical distortion ratio varied from mean of 1.00 in incisor and canine region to 1.04 in molar region on JPEG image format with calibration achieved by the metal ruler being positioned in the middle of the panoramic radiograph, similarly as in DICOM image format. When measurements were performed in horizontal direction, it was found that differences could be related to the position of a specific tooth within each dental arch. The most accurate measurements in horizontal direction with the calibration metal ruler placed in the middle of the panoramic radiograph were registered in molar region (G4) in both JPEG $(6.09 \pm 0.21 \mathrm{~mm}, P=0.021)$ and DICOM image formats $(6.08 \pm 0.21 \mathrm{~mm}, P=0.033)$, while the same measurements in other three groups were less precise. Our results of horizontal measurements of 32 metal balls on digital panoramic radiographs are in agreement with similar measurements performed in other studies [16, 25, 26]. Vertical measurements in both JPEG and DICOM image formats, regardless of the calibration object position, were very different when compared to the horizontal measurements. The $95 \%$ confidence interval revealed differences between horizontal and vertical measurements, depending on the position of the calibration object. For vertical measurements, in JPEG and DICOM image formats with a calibration object positioned sideways, there was statistical significance in all groups of teeth. However, in horizontal measurements, there was no statistical significance within the groups of teeth. Although the differences of the horizontally measured objects in our study were statistically significant, it is questionable how it can be implicated in the clinical practice. Dental clinicians should be aware of the distance overestimation between the upper limit of the alveolar ridge and the upper limit 
of the mandibular canal, as it can lead to the implant insertion in the mandibular canal causing paresthesia [19, 24, 27, 28]. Also, the underestimation of the available bone height may lead the choosing of the smaller implant than needed, which can compromise the treatment success [24]. Therefore, in certain clinical cases it would be advantageous to use more precise radiological techniques such as new generation of dental panoramic radiographic equipment with tomosynthesis and cone beam computed tomography (CВCT) $[4-6,29,30]$.

Previous studies have shown that digital panoramic radiography is reliable method for vertical measurements, mainly in posterior region of the mandible [11-19]. Vazquez et al. evaluated the measurement accuracy of digital panoramic radiographs using posterior mandibular implants and metal balls as reference objects and showed reliable accuracy in both modalities [14]. They did not find any significant differences in the vertical measurements of implants (the mean vertical $\mathrm{DR}=0.99$ ) and metal balls (the mean vertical $\mathrm{DR}=0.97$ ), respectively, and the accuracy was unrelated to the mandibular sites [14]. Many previous studies reported the accuracy of vertical measurements on digital panoramic radiographs but there is limited evidence regarding the accuracy of horizontal measurements [14, 19-25].

The limitation of this study was the lack of in vivo characteristics of our model. Since teeth with different positions within the dental arch appear slightly different on radiographs, mainly due to the distortion, we believe that extra-oral placing of the calibration device, so that it appears in the middle of the image, can reduce measuring errors. However, our results need to be confirmed in future in vivo studies.

Provenance: Submitted. Based on the master's thesis by Anita Ivanović, deposited in the DABAR repository (https://urn.nsk.hr/urn:nbn:hr:176:521337).

Received: 23 October 2019 / Accepted: 22 January 2020 / Published online: 18 May 2020.

Peer review: Externally peer reviewed.

Funding: None.

Authorship declaration: Anita Ivanović contributed to acquisition, analysis and interpretation of the data; drafting and providing final approval of the version to be published; Frane Mihanović contributed to the design and concept; acquisition, analysis and interpretation of the data; drafting and critical revision, supervision of the study; and providing final approval of the version to be published. The authors are agreement to be accountable for all aspects of the work in ensuring that questions related to the accuracy or integrity of any part of the work are appropriately investigated and resolved.

Competing interests: The authors completed the ICMJE Unified Competing Interest form (available upon request from the corresponding author), and declare no conflicts of interest.

\section{ORCID}

Anita Ivanović (iD https://orcid.org/0000-0002-6845-192X 


\section{References}

1. Perschbacher S. Interpretation of panoramic radiographs. Aust Dent J. 2015;1:40-5.

2. Harris D, Buser D, Dula K, Grondahl K, Haris D, Jacobs R et al. E.A.O. guidelines for the use of diagnostic imaging in implant dentistry. A consensus workshop organized by the European Association for Osseointegration in Trinity College Dublin. Clin Oral Implants Res. 2002;13(5):566-70.

3. Van der Stelt PF. Better imaging: the advantages of digital radiography. J Am Dent Assoc.2008;139:7S-13S.

4. Whaites E, Drage N. Radiography and radiology for dental care professionals. 3rd ed. London: Churchil Livingstone Elsevier; 2013.

5. Tyndall D, Price JB, Tetradis S, Ganz SD, Hildebolt C, Scarfe WC. Position statement of the American Academy of Oral and Maxillofacial Radiology on selection criteria for the use of radiology in dental implantology with emphasis on cone beam computed tomography. Oral Surg Oral Med Oral Pathol Oral Radiol. 2012;113:817-26.

6. Farman AG. Applying DICOM to dentistry. J Digit Imaging. 2005;18:23-7.

7. Medical Imaging \& Technology Alliance. The DICOM standard 2015. Rosslyn, VA, 2015. Available: http://www.dicom.nema.org/standard.html. Accessed: 30 July 2015.

8. Nair MK, Pettigrew JC Jr, Loomis JS, Bates RE, Kostewicz S, Robinson B et al. Enterprise-wide implementation of digital radiography in oral and maxillofacial imaging: the University of Florida Dentistry System. J Digit Imaging. 2009;22:232-41.

9. Tronje G, Welander U, McDavid WD, Morris CR. Image distortion in rotational panoramic radiography. I. General considerations. Acta Radiol Diagn (Stockh). 1981;22:295-9.

10. Tronje G, Eliasson S, Julin P, Welander U. Image distortion in rotational panoramic radiography. II. Vertical distances. Acta Radiol Diagn (Stockh). 1981;22:449-55.

11. Schulze R, Krummenauer F, Schalldach F, d'Hoedt B. Precision and accuracy of measurements in digital panoramic radiography. Dentomaxillofac Radiol. 2000;29:52-6.

12. Stramotas SGJ, Petocz P, Darendeliler MA. Accuracy of linear and angular measurements on panoramic radiographs taken at various positions in vitro. Eur J Orthod. 2002;24:43-52.

13. Ladeira DBS, Cruz AD, Almeida SM, Boscolo FN. Influence of the intergonial distance on image distortion in panoramic radiographs. Dentomaxillofac Radiol. 2012;41:417-21.

14. Vazquez L, Nizamaldin Y, Combescure C, Nedir R, Bischof M, Dohan Ehrenfest DM et al. Accuracy of vertical height measurements on direct digital panoramic radiographs using posterior mandibular implants and metal balls as reference objects. Dentomaxillofac Radiol. 2013;42:20110429.

15. Nikneshan S, Sharafi M, Emadi N. Evaluation of the accuracy oflinear and angular measurements on panoramic radiographs taken at different positions. Imaging Sci Dent. 2013;43:191-6.

16. Schropp L, Stavropoulus A, Gotfredsen E, Wenzel A. Calibration of radiographs by a reference metal ball affects preoperative selection of implant size. Clin Oral Investig. 2009;13:375-81.

17. Kamburoglu K, Kurt H, Kolsuz E, Oztas B, Tatar I, Celik HH. Occlusal caries depth measurements obtained by five different imaging modalities. J Digit Imaging. 2011;24:804-13.

18. Kim YK, Park JY, Kim SG, Kim JS, Kim JD. Magnification rate of digital panoramic radiographs and its effectiveness for preoperative assessment of dental implants. Dentomaxillofacial Radiol. 2011;40:76-83.

19. Vazquez L, Saulacic N, Belser U, Bernard JP. Efficacy of panoramic radiographs in the preoperative planning of posterior mandibular implants: a prospective clinical study of 1527 consecutively treated patients. Clin Oral Implants Res. 2008;19:81-5.

20. Choi YG, Kim YK, Eckert SE, Shim CH. Cross-sectional study of the factors that influence radiographic magnification of implant diameter and length. Int J Maxillofac Implants. 2004;19:594-6.

21. Vazquez L, Nizam Al Din Y, Belser UC, Combescure C, Bernard JP. Reliability of the vertical magnification factor on panoramic radiographs: clinical implications for posterior mandibular implants. Clin Oral Impl Res. 2011;22:1420-25. 
22. El Hage M, Bernard JP, Combescure C, Vazquez L. Impact of digital panoramic radiograph magnification on vertical measurement accuracy. Int J Dent.2015;2015:452413.

23. Wakoh M, Harada T, Otonari T, Otonari-Yamamoto M, Ohkubo M, Kousuge Y et al. Reliability of linear distance measurement for dental implant length with standardized periapical radiographs. Bull Tokyo Dent Coll. 2006;47:105-15.

24. Langlois Cde O, Sampaio MC, Silva AE, Costa NP, Rockenbach MI. Accuracy of linear measurements before and after digitizing periapical and panoramic radiography images. Braz Dent J. 2011;22:404-9.

25. Catic A, Celebic A, Valentic-Peruzovic M, Catovic A, Kuna T. Dimensional measurements on the human dental panoramic radiographs. Coll Antropol. 1998;22:139-45.

26. The American Dental Association Council on Scientific Affairs: The use of cone-beam computed tomography in dentistry. An advisory statement from the American Dental Association Council on Scientific Affairs. J Am Dent Assoc. 2012;143:899-902.

27. Devlin H, Yuan J. Object position and image magnification in dental panoramic radiography: a theoretical analysis. Dentomaxillofac Radiol. 2013;42:29951683.

28. Liu W, Yin W, Zhang R, Li J, Zheng Y. Diagnostic value of panoramic radiography in predicting inferior alveolar nerve injury after mandibular third molar extraction: a meta-analysis, Aust Dent J. 2015;60:233-9.

29. Kitai NY, Mukai Y, Murabayashi M, Kawabata A, Washino K, Matsuoka M et al. Measurement accuracy with a new dental panoramic radiographic technique based on tomosynthesis. Angle Orthod. 2013;83:117-26.

30. Muinelo-Lorenzo J, Suárez-Quintanilla JA, Fernández-Alonso A, Varela-Mallou J, SuárezCunqueiro MM. Anatomical characteristics and visibility of mental foramen and accessory mental foramen: Panoramic radiography vs. cone-beam CT. Med Oral Patol Oral Cir Bucal. 2015;20:707-14. 